\title{
Clinical Issues in Use of Atypical Antipsychotics for Depressed Patients
}

\author{
Chi-Un Pae $\cdot$ Ashwin A. Patkar
}

Published online: 25 May 2013

(C) Springer International Publishing Switzerland 2013

\begin{abstract}
Major depressive disorder (MDD) is a chronic, recurrent mental disease that causes serious disability. Because currently available antidepressants have limited efficacy with respect to response and remission in patients with MDD, clinicians must choose the best available treatment interventions for patients who do not respond to initial antidepressant treatment. The existing literature demonstrates that augmentation with atypical antipsychotics (AAs) shows higher response and remission rates compared with antidepressant monotherapy, but is associated with more withdrawals due to adverse events. In this paper, specific clinical issues in the use of AA augmentation for patients with MDD are briefly discussed. Given the limited information and clinical knowledge on the proper and effective use of AAs for MDD, future research should focus on practical clinical issues that can be commonly seen in routine practice but have not been addressed yet. This is because the use of AAs is likely to expand as there is good evidence for their effectiveness and tolerability as augmentation therapy for patients with MDD.
\end{abstract}

Previous Presentation: Part of the information presented in this article was presented at the round table discussion of psychiatrists from Asia and the USA, sponsored by Korea Otsuka International Asia and Arab.

C.-U. Pae $(\bowtie)$

Department of Psychiatry, Bucheon St Mary's Hospital,

The Catholic University of Korea, College of Medicine,

2 Sosa-Dong, Wonmi-Gu, Bucheon, Kyounggi-Do 420-717,

Republic of Korea

e-mail: pae@catholic.ac.kr

C.-U. Pae · A. A. Patkar

Department of Psychiatry and Behavioral Sciences, Duke

University Medical Center, Durham, North Carolina, USA

\section{Introduction}

Major depressive disorder (MDD) is a highly prevalent chronic mental disorder [1]. The prevalence of MDD is estimated to be approximately $16 \%$ during an individual's lifetime and $7 \%$ during a 1-year period [1]. MDD is also the third leading cause of moderate and severe disability and of disease burden worldwide, and causes a high economic burden of mainly work-related costs, a high suicide rate and vast impairment in quality of life [1]. Currently, the main biological treatment for MDD is various antidepressants such as selective serotonin reuptake inhibitors, dopamine-norepinephrine reuptake inhibitors, serotoninnorepinephrine reuptake inhibitors and noradrenergic and specific serotonin antagonists, which were mainly developed under a monoamine hypothesis [2, 3].

However, previous placebo controlled clinical studies along with the Sequenced Treatment Alternatives to Relieve Depression (STAR*D) [4] and Combining Medications to Enhance Depression Outcomes (CO-MED) [5] trials have clearly demonstrated limited therapeutic outcomes with appropriate antidepressant treatments in patients with MDD. In particular, lower response (remission) and higher relapse rates were clearly observed among those who required additional treatment steps in the STAR*D trial [4]. Hence, most currently available treatment guidelines recommend that nonresponders or partial responders should be considered for a switch, combination, or augmentation of treatment based on the patient's clinical situation (Fig. 1) [6-9].

The traditional augmentation agents include lithium, triiodothyronine, buspirone, dopamine agonists and stimulants, but have very limited supporting data [10]. Recently, augmentation of antidepressant therapy with atypical antipsychotics (AAs) has become a more widely 


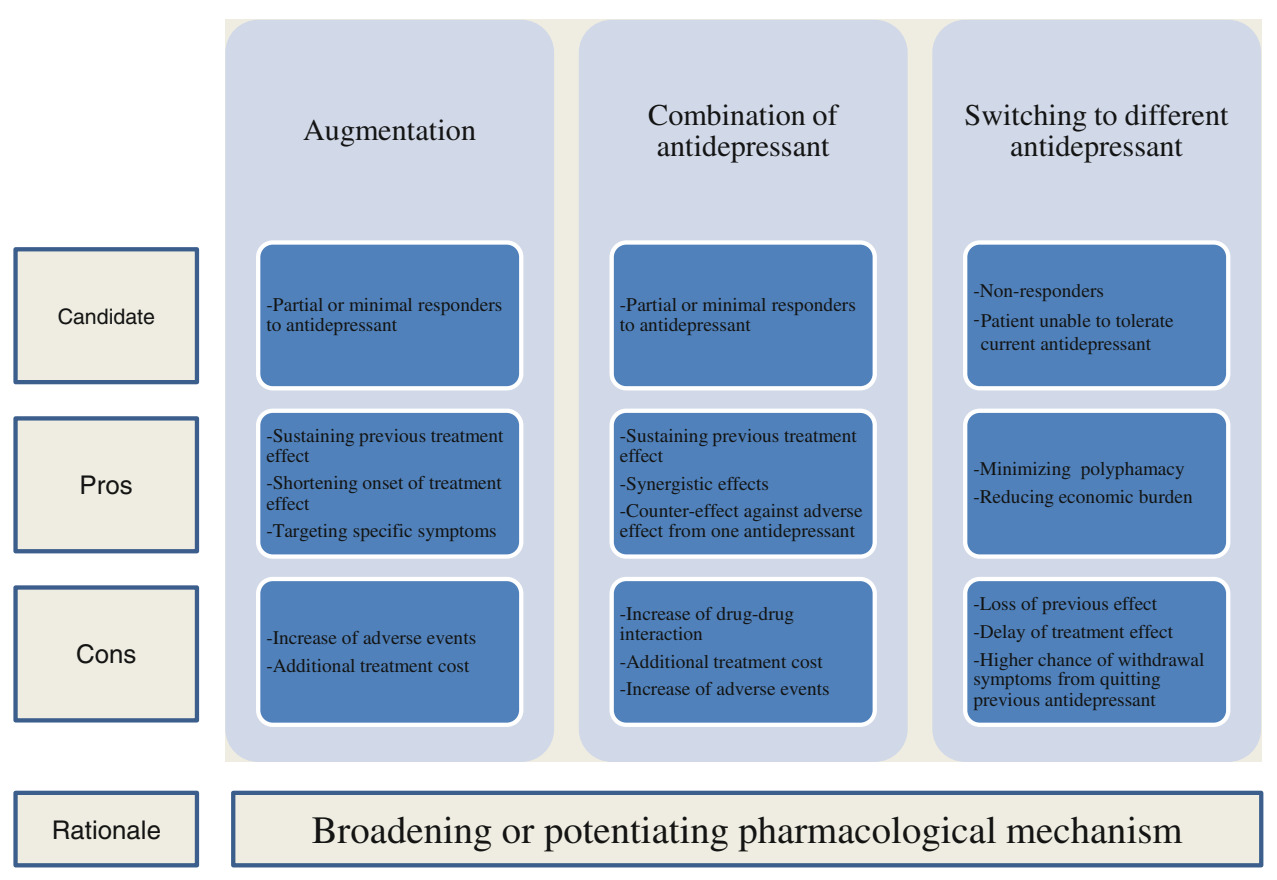

Fig. 1 Pharmacological treatment options for failure of initial antidepressant treatment

accepted treatment practice, with official approval from regulatory authorities.

\section{Currently Available Atypical Antipsychotics for Major Depressive Disorder}

Various AAs have demonstrated a positive antidepressant effect in a number of small-scale, open-label studies or randomized, placebo controlled clinical trials. In fact, the use of AAs in MDD has also dramatically increased and continues to be one of the best available augmentation options. Some of these agents (aripiprazole and quetiapine $\mathrm{XR}$ ) have recently been approved for treatment of MDD as augmentation therapy by the US Food and Drug Administration. Among those agents, aripiprazole has been approved as an augmentation therapy for treating MDD in South Korea, Taiwan, Hong Kong, Thailand, the Philippines, Indonesia and Egypt.

Aripiprazole and quetiapine XR were approved for augmentation treatment of MDD in 2007 and 2009, respectively, whereas an olanzapine/fluoxetine combination (marketed as Symbyax) was also approved for treatment-resistant depression in 2009. There is also some limited evidence of the effects of other AAs for the treatment of MDD (ziprasidone, risperidone, amisulpride, etc.) [11]. Although the exact mechanism of AAs for MDD has not yet been clearly elucidated, several plausible underlying mechanisms such as the modulation of diverse neurotransmitter receptors and transporters other than dopamine [serotonin (5HT) 1A, 5HT2A/2B, 5HT2C, 5HT6, 5HT7, $\alpha-2$ receptor, norepinephrine transporter, etc.], effects on sleep, effects on various hormones (adrenocorticotrophic hormone, sex hormones, etc.), alteration of immune functions (cytokines, etc.), and modulation of neurotrophic factors (brain-derived neurotrophic factor, etc.) may partly explain the antidepressant effects [12].

Based on placebo controlled clinical trials, aripiprazole has clearly shown efficacy as an augmentation therapy [13]. However, it is also associated with more adverse events (AEs) than antidepressant monotherapy in patients with MDD [13]. In particular, the rate of extrapyramidal symptoms (EPSs) was significantly higher than that of placebo [13]. In fact, the occurrence of akathisia in MDD trials was approximately four times (approximately $23 \%$ ) higher than that $(6 \%)$ seen in schizophrenia trials [13]. Other AAs have also demonstrated beneficial effects and potentially different AE profiles [14, 15]. An elevated risk of weight gain is commonly seen in all AAs. However, an olanzapine-fluoxetine combination is associated with more profound weight gain, whereas risperidone and quetiapine XR show more prolactin increase and sedation, respectively, compared with placebo [11]. Clinicians should also routinely monitor for cardiometabolic side effects and EPSs during augmentation AA therapy [14]. No sufficient data support the superiority of any individual AA over other agents in the treatment of MDD. These points were also replicated in a number of meta-analyses $[11,16]$. The efficacy of these agents was not affected by the clinical trial duration or method of establishing treatment failure. 
Although limited data suggest that AAs may have better efficacy as monotherapy than augmentation therapy in the treatment of MDD, augmentation is more widely utilized in treatment-resistant depression.

\section{Clinical Issues in the Use of Atypical Antipsychotics in Clinical Practice}

As stated above, augmentation, combination and switching strategies are available for partial or nonresponders to current antidepressants. However, no supporting data are available regarding the superiority of one strategy over other treatment options. As was seen in surveys with clinicians and treatment choice in the STAR*D trial, augmentation is potentially favoured in partial responders [1722]. This is primarily based on practical considerations, namely that the addition of a second agent allows the initial response to be maintained, whereas a switch might not. In addition, although combination approaches are common in clinical practice, the evidence is quite limited.

What is the best timing for augmentation treatment for our patients? Considering aripiprazole registration trials, selection criteria were historical failure of one to three adequate treatments with a marketed antidepressant during the current episode of MDD (approximately $70 \%$ of patients had one failure) and a prospective failure of one antidepressant treatment. Acute remission rates in MDD are greatest with the first two sequential treatments [4]. Given findings from previous antipsychotic augmentation trials, at least two antidepressant failures would be reasonable to commence antipsychotic augmentation in such MDD patients [23-25]. However, a recent study has suggested that augmentation with low-dose aripiprazole ( $2.5 \mathrm{mg} /$ day) could augment the efficacy of regular-dose sertraline in treatment-naive MDD [26], indicating that augmentation AAs may also be used at an earlier treatment stage for patients with MDD, and quetiapine XR trials also suggest that AA augmentation could be used after one antidepressant failure [15].

The number needed to treat (NNT) and number needed to harm $(\mathrm{NNH})$ are very useful values for clinicians to interpret the relevance of clinical trial results compared with traditional statistical information (such as the $p$ value, etc.), which cannot explain the clinical importance of results [27]. In registration studies of aripiprazole, olanzapine-fluoxetine combination and quetiapine XR, the NNT for response and remission ranged from 7 to 14 and from 7 to 13, respectively, depending on the antipsychotic and/or dose [13, 15, 28]. As described above, AE profiles for aripiprazole, olanzapine and quetiapine XR are diverse; aripiprazole is more strongly associated with akathisia $(\mathrm{NNH}=6)$, whereas olanzapine is more strongly associated with weight gain $(\mathrm{NNH}=3)$ and quetiapine $\mathrm{XR}$ with somnolence $(\mathrm{NNH}=5$ for $300 \mathrm{mg} /$ day and $\mathrm{NNH}=6$ for $150 \mathrm{mg} /$ day) $[13,15,28]$. When we carefully consider the NNT or NNH with each antipsychotic, we can also address the point of benefits against risk in the selection of the best available medication in clinical practice.

Although the registration studies of aripiprazole, olanzapine and quetiapine XR were not designed to identify the proper dose for treating patients with MDD, we may learn some lessons about the daily dose of an individual AA from the dose findings of such trials. The mean daily dose of aripiprazole was approximately $11.0 \mathrm{mg} /$ day [13]. On average, patients achieved a terminal dose at week 3, maintaining this dose for the remainder of the study. The dosing trend did not differ meaningfully across the individual antidepressants. It has been suggested that a starting dose of $2-5 \mathrm{mg} /$ day with a target dose of $5-15 \mathrm{mg} /$ day is prudent for MDD [11, 13, 15]. The starting dose of quetiapine XR may be $50 \mathrm{mg} /$ day, with a target dose of 150-300 mg/day [15]. According to the results from registration trials, quetiapine $\mathrm{XR}$ could be increased up to $300 \mathrm{mg} /$ day after 2 weeks of treatment if the patient shows an inadequate response to the initial dose [13]. However, $300 \mathrm{mg} /$ day of quetiapine XR caused more discontinuation due to AEs than $150 \mathrm{mg} /$ day. Therefore, $150 \mathrm{mg} /$ day of quetiapine XR should be tried initially and then titrated up to $300 \mathrm{mg} / \mathrm{day}$ in routine practice. Olanzapine and risperidone doses ranged from 5 to $20 \mathrm{mg} /$ day (target dose $10-15 \mathrm{mg} /$ day) and from 0.25 to $3 \mathrm{mg} /$ day (target dose $1 \mathrm{mg} /$ day), respectively [29]. Ziprasidone and amisulpride doses ranged from 80 to $160 \mathrm{mg} /$ day and from $50 \mathrm{mg} /$ day in small-scale open or randomized controlled studies [3032]. For dysthymia, $50 \mathrm{mg} /$ day of amisulpride was tested as monotherapy or as an augmentation agent [31, 33]. Although there is no clear evidence indicating a doseresponse relationship in such antipsychotic augmentation studies, a trend has been found towards increased intolerability with gradual dosing increments [11, 13, 15]. Therefore, initiation at a low dose with slow titration to the target dose should be performed to maximize the adequate response and minimize the occurrence of unwanted AEs in AA augmentation for patients with MDD. Table 1 summarizes the proper dose ranges of AAs based on findings from depression trials.

Early improvement in depressive symptoms with antidepressant treatment may predict a favourable treatment outcome [34-39]. Studies on the association between the onset time of antidepressant response and the probability of response have yielded some intriguing findings, although debates still continue. However, evidence from clinical trials of aripiprazole, quetiapine XR and olanzapine for MDD demonstrated that an initial response can be 
Table 1 Dose ranges and common adverse events of atypical antipsychotics in depression trials [13, 15, 29-33, 51]

\begin{tabular}{|c|c|c|c|}
\hline Drug & $\begin{array}{l}\text { Duration } \\
\text { (weeks) }\end{array}$ & Dose range & AEs \\
\hline Olanzapine* & $8-12$ & $5-20 \mathrm{mg} /$ day with various combinations; mean dose $8-14 \mathrm{mg} /$ day & $\begin{array}{l}\text { Weight gain: } 4 \mathrm{~kg} \text { for } \\
8 \text { weeks }\end{array}$ \\
\hline Risperidone* & $4-6$ & $\begin{array}{l}0.5-3.0 \mathrm{mg} / \text { day; mean dose } 1.2-1.6 \mathrm{mg} / \text { day; } 1-1.5 \mathrm{mg} / \text { day with minimal risk } \\
\text { of developing AEs }\end{array}$ & Hyperprolactinaemia \\
\hline Quetiapine* & $8-52$ & $50-300 \mathrm{mg} /$ day in flexible and fixed dose trials; mean dose $180 \mathrm{mg} / \mathrm{day}$ & Sedation and weight gain \\
\hline Aripiprazole* & $6-52$ & $5-15 \mathrm{mg} /$ day; mean dose $11-12 \mathrm{mg} /$ day & EPS including akathisia \\
\hline Ziprasidone $* *$ & 6 & $80-160 \mathrm{mg} /$ day & $\begin{array}{l}\text { Most common AE was } \\
\text { insomnia }\end{array}$ \\
\hline Amisulpride*** & $8-24$ & $50 \mathrm{mg} /$ day in MDD and dysthymia & $\begin{array}{l}\text { Sexual dysfunction and } \\
\text { weight gain }\end{array}$ \\
\hline
\end{tabular}

* Placebo controlled studies, ** only open-label study, *** open-label and randomized controlled studies for MDD and dysthymia. $A E$ adverse event, $E P S$ extrapyramidal symptoms, $M D D$ major depressive disorder

observed in 1 or 2 weeks $[13,15,40]$. In fact, augmentation may lead to a more rapid response and remission compared with a switching strategy because no time is lost titrating the initial and next antidepressants.

A differential augmentation effect of aripiprazole and quetiapine XR by antidepressant class was not observed in individual trials $[13,15]$. Therefore, currently available data suggest that augmentation AAs may produce a similar augmentation effect regardless of antidepressant class. In addition, there has been no such information supporting the superiority of specific AAs over other AAs as an augmentation therapy for MDD based on a recent, large metaanalysis [11].

Some data showed different response and remission based on the antidepressant class and the type of MDD such as anxious depression and atypical depression [41, 42], for example, favouring monoamine oxidase inhibitors over tricyclic antidepressants for atypical MDD. Symptom severity, clinical course/outcome and functioning may be worse in patients with atypical/anxious depression than in those without $[43,44]$. According to retrospective analyses of pooled data of aripiprazole and quetiapine XR, they may be effective and reliable augmentation agents for patients with MDD regardless of the presentation of subdepressive symptoms, depression severity, past treatment response, or previous antidepressant treatment failure [45-49]. No clinical factors predicting response to augmentation antipsychotics have been found in patients with MDD.

No new cases of tardive dyskinesia (TD) were observed in short-term clinical trials of AAs for MDD [13, 15]. However, when we consider that the duration of most trials varied from 4 to 12 weeks, such short-term trial duration may not accurately evaluate a potential development of TD in patients with MDD. Currently, we have only two 52-week maintenance studies each in aripiprazole and quetiapine XR for MDD [50, 51]. There were four spontaneous reports of TD in aripiprazole's 52-week longterm study, although all four cases resolved with dose reduction or drug discontinuation. There was no TD case in a 24-week open-label extension study of olanzapine-fluoxetine combination and olanzapine monotherapy, although it was investigated in bipolar depression [52]. More than 1 year of maintenance treatment with AAs is not yet supported by any evidence or clinical practice.

Treatment costs should also affect the choice of augmentation agents in clinical practice. Healthcare utilization and expenditures were analysed using claims data from 2001 to 2009 in patients with MDD treated with antidepressants and AAs [53]. In that study, mean adjusted expenditures for aripiprazole were significantly lower than those for olanzapine and quetiapine for most of each service category (all-cause, all-cause medical care, mental health and mental health-related medical care). In addition, aripiprazole significantly lowered the chance of hospitalization and emergency department visits compared with quetiapine. Clinicians may also consider currently available pharmacoeconomic vigilance data in clinical practice.

Polymorphisms in the cytochrome P450 2D6 (CYP2D6) gene are a major cause of pharmacokinetic variability in humans, and sufficient evidence suggests ethnic differences in the metabolism of antipsychotics between Asian and western populations $[54,55]$. For instance, fluoxetine and paroxetine, which are potent CYP2D6 inhibitors, will raise aripiprazole blood levels and thus a lower dose might be used in clinical practice. In fact, some open-label studies involving Asian populations suggested a potential difference in the optimal dose of aripiprazole augmentation for treating MDD [56-58]. The mean daily doses of augmentation aripiprazole in studies involving Asian patients (2-8 $\mathrm{mg}$ /day) were substantially lower than those in studies involving Caucasian patients (11-12 mg/day). Additional studies are required to confirm whether ethnic differences 
in proper dosing exist, particularly in terms of pharmacokinetics, for patients with MDD.

\section{Conclusions}

Clinicians may have different biological treatment strategies to enhance the treatment outcomes of initial antidepressants, as recommended in the diverse treatment guidelines [6] and as evidenced in the large practical clinical studies [4] and a large survey [59]. However, no clear evidence exists regarding which strategy among the options of augmentation, combination and switching therapy would be the best option for patients with an inadequate response. There is a paucity of controlled data regarding a direct comparison of such strategies.

In addition, differential effects among AAs for treating MDD have not been studied. Which antipsychotic is more beneficial or harmful for a specific patient population? Comparisons among antipsychotics, lithium, thyroid medications, or other augmentation agents have not been conducted. Therefore, subsequent well-designed studies that address whether there is a clear benefit of adjunctive AAs for treating patients with MDD compared with other augmentation agents and treatment strategies may determine their clear utility in real-world clinical practice.

Some evidence indicates that the initiation of augmentation or combination strategies earlier in the treatment phase may enhance the chance of response or remission [4, 19, 60]. However, this strategy has been rarely studied. Potential but serious AEs with AAs such as weight gain, metabolic syndrome and TD are not detectable in shortterm treatment; thus more long-term studies will be mandatory.

Ethnic differences, especially in terms of the dosing schedule and AEs, should also be investigated. Currently available findings indicate that clinicians should consider the potential risk/benefit analysis on a patient-by-patient basis when making a decision to prescribe augmentation AAs. Future adequately powered and well-designed studies will provide more valuable and practical information about the use of augmentation AAs for patients with MDD.

\footnotetext{
Acknowledgments Although Korea Otsuka International Asia and Arab (KOIAA) was involved in supporting the production of the supplement, the content of the manuscript, its review and revision, and the decision to submit to CNS Drugs were made solely by the authors and the supplement guest editor.
}

Sources of Financial Support The authors did not receive honorarium for writing this manuscript.

Conflict of interest Dr Pae has received research grant from Eisai Korea, Janssen Pharmaceuticals Korea, Korean Health Technology R\&D Project, Ministry of Health \& Welfare, Republic of Korea and
Korean Research Foundation; and has received honoraria from Pfizer Korea and Otsuka Korea. Dr Patkar is a consultant for Bristol-Myers Squibb, GlaxoSmithKline and Reckitt Benckiser; is on the speaker's bureau of Bristol-Myers Squibb, GlaxoSmithKline and Reckitt Benckiser; and has received research support from National Institutes of Health, AstraZeneca, Bristol-Myers Squibb, Forest, GlaxoSmithKline, Janssen, McNeil Consumer and Specialty Inc, Organon, Jazz Pharmaceuticals and Pfizer.

Disclosure This manuscript has been published in a journal supplement that was created with an unrestricted educational grant from Korea Otsuka International Asia and Arab (KOIAA).

\section{References}

1. Kessler RC, Berglund P, Demler O, Jin R, Koretz D, Merikangas $\mathrm{KR}$, et al. The epidemiology of major depressive disorder: results from the National Comorbidity Survey Replication (NCS-R). JAMA. 2003;289(23):3095-105.

2. Fava M, Rush AJ, Trivedi MH, Nierenberg AA, Thase ME, Sackeim HA, et al. Background and rationale for the sequenced treatment alternatives to relieve depression (STAR*D) study. Psychiatr Clin North Am. 2003;26(2):457-94; x.

3. Trivedi MH, Rush AJ, Wisniewski SR, Nierenberg AA, Warden D, Ritz L, et al. Evaluation of outcomes with citalopram for depression using measurement-based care in STAR*D: implications for clinical practice. Am J Psychiatry. 2006;163(1):28-40.

4. Rush AJ, Trivedi MH, Wisniewski SR, Nierenberg AA, Stewart JW, Warden D, et al. Acute and longer-term outcomes in depressed outpatients requiring one or several treatment steps: a STAR*D report. Am J Psychiatry. 2006;163(11):1905-17.

5. Rush AJ, Trivedi MH, Stewart JW, Nierenberg AA, Fava M, Kurian BT, et al. Combining medications to enhance depression outcomes (CO-MED): acute and long-term outcomes of a single-blind randomized study. Am J Psychiatry. 2011;168(7): 689-701.

6. American Psychiatric Association. Practice guideline for the treatment of patients with major depressive disorder (revision). Am J Psychiatry. 2000;157(4 Suppl.):1-45.

7. Bauer M, Whybrow PC, Angst J, Versiani M, Moller HJ. World Federation of Societies of Biological Psychiatry (WFSBP) guidelines for biological treatment of unipolar depressive disorders, Part 1: Acute and continuation treatment of major depressive disorder. World J Biol Psychiatry. 2002;3(1):5-43.

8. Anderson IM, Ferrier IN, Baldwin RC, Cowen PJ, Howard L, Lewis G, et al. Evidence-based guidelines for treating depressive disorders with antidepressants: a revision of the 2000 British Association for Psychopharmacology guidelines. J Psychopharmacol. 2008;22(4):343-96.

9. Kennedy SH, Lam RW, Cohen NL, Ravindran AV. Clinical guidelines for the treatment of depressive disorders. IV. Medications and other biological treatments. Can J Psychiatry; Revue canadienne de psychiatrie. 2001;46(Suppl. 1):38S-58S.

10. Philip NS, Carpenter LL, Tyrka AR, Price LH. Augmentation of antidepressants with atypical antipsychotics: a review of the current literature. J Psychiatr Pract. 2008;14(1):34-44.

11. Nelson JC, Papakostas GI. Atypical antipsychotic augmentation in major depressive disorder: a meta-analysis of placebo-controlled randomized trials. Am J Psychiatry. 2009;166(9):980-91.

12. Sagud M, Mihaljevic-Peles A, Begic D, Vuksan-Cusa B, Kramaric $\mathrm{M}$, Zivkovic $\mathrm{M}$, et al. Antipsychotics as antidepressants: what is the mechanism? Psychiatr Danub. 2011;23(3):302-7. 
13. Pae CU, Forbes A, Patkar AA. Aripiprazole as adjunctive therapy for patients with major depressive disorder: overview and implications of clinical trial data. CNS Drugs. 2011;25(2):109-27.

14. Chen J, Gao K, Kemp DE. Second-generation antipsychotics in major depressive disorder: update and clinical perspective. Curr Opin Psychiatry. 2011;24(1):10-7.

15. Pae CU, Sohi MS, Seo HJ, Serretti A, Patkar AA, Steffens DC, et al. Quetiapine XR: current status for the treatment of major depressive disorder. Prog Neuropsychopharmacol Biol Psychiatry. 2010;34(7):1165-73.

16. Papakostas GI, Shelton RC, Smith J, Fava M. Augmentation of antidepressants with atypical antipsychotic medications for treatment-resistant major depressive disorder: a meta-analysis. J Clin Psychiatry. 2007;68(6):826-31.

17. Mischoulon D, Nierenberg AA, Kizilbash L, Rosenbaum JF, Fava M. Strategies for managing depression refractory to selective serotonin reuptake inhibitor treatment: a survey of clinicians. Can J Psychiatry; Revue Canadienne de Psychiatrie. 2000;45(5): 476-81.

18. Gaynes BN, Dusetzina SB, Ellis AR, Hansen RA, Farley JF, Miller WC, et al. Treating depression after initial treatment failure: directly comparing switch and augmenting strategies in STAR*D. J Clin Psychopharmacol. 2012;32(1):114-9.

19. Rush AJ, Warden D, Wisniewski SR, Fava M, Trivedi MH, Gaynes BN, et al. STAR*D: revising conventional wisdom. CNS Drugs. 2009;23(8):627-47.

20. Wisniewski SR, Fava M, Trivedi MH, Thase ME, Warden D, Niederehe G, et al. Acceptability of second-step treatments to depressed outpatients: a STAR*D report. Am J Psychiatry. 2007; 164(5):753-60.

21. Warden D, Rush AJ, Wisniewski SR, Lesser IM, Kornstein SG, Balasubramani GK, et al. What predicts attrition in second step medication treatments for depression?: a STAR*D Report. Int J Neuropsychopharmacol. 2009;12(4):459-73.

22. Papakostas GI, Petersen TJ, Green C, Iosifescu DV, Yeung AS, Nierenberg AA, et al. A description of next-step switching versus augmentation practices for outpatients with treatment-resistant major depressive disorder enrolled in an academic specialty clinic. Ann Clin Psychiatry Off J Am Acad Clin Psychiatr. 2005;17(3):161-5.

23. Berman RM, Fava M, Thase ME, Trivedi MH, Swanink R, McQuade RD, et al. Aripiprazole augmentation in major depressive disorder: a double-blind, placebo-controlled study in patients with inadequate response to antidepressants. CNS Spectr. 2009;14(4):197-206.

24. Berman RM, Marcus RN, Swanink R, McQuade RD, Carson WH, Corey-Lisle PK, et al. The efficacy and safety of aripiprazole as adjunctive therapy in major depressive disorder: a multicenter, randomized, double-blind, placebo-controlled study. J Clin Psychiatry. 2007;68(6):843-53.

25. Marcus RN, McQuade RD, Carson WH, Hennicken D, Fava M, Simon JS, et al. The efficacy and safety of aripiprazole as adjunctive therapy in major depressive disorder: a second multicenter, randomized, double-blind, placebo-controlled study. J Clin Psychopharmacol. 2008;28(2):156-65.

26. Lin $\mathrm{CH}$, Lin SH, Jang FL. Adjunctive low-dose aripiprazole with standard-dose sertraline in treating fresh major depressive disorder: a randomized, double-blind, controlled study. J Clin Psychopharmacol. 2011;31(5):563-8.

27. Citrome L. Number needed to treat: what it is and what it isn't, and why every clinician should know how to calculate it. J Clin Psychiatry. 2011;72(3):412-3.

28. Citrome L. Adjunctive aripiprazole, olanzapine, or quetiapine for major depressive disorder: an analysis of number needed to treat, number needed to harm, and likelihood to be helped or harmed. Postgrad Med. 2010;122(4):39-48.
29. Owenby RK, Brown LT, Brown JN. Use of risperidone as augmentation treatment for major depressive disorder. Ann Pharmacother. 2011;45(1):95-100.

30. Dunner DL, Amsterdam JD, Shelton RC, Loebel A, Romano SJ. Efficacy and tolerability of adjunctive ziprasidone in treatmentresistant depression: a randomized, open-label, pilot study. J Clin Psychiatry. 2007;68(7):1071-7.

31. Rocca P, Marchiaro L, Rasetti R, Rivoira E, Bogetto F. A comparison of paroxetine versus paroxetine plus amisulpride in the treatment of dysthymic disorder: efficacy and psychosocial outcomes. Psychiatry Res. 2002;112(2):145-52.

32. Rocca P, Fonzo V, Ravizza L, Rocca G, Scotta M, Zanalda E, et al. A comparison of paroxetine and amisulpride in the treatment of dysthymic disorder. J Affect Disord. 2002;70(3):313-7.

33. Zanardi R, Smeraldi E. A double-blind, randomised, controlled clinical trial of acetyl-L-carnitine vs. amisulpride in the treatment of dysthymia. Eur Neuropsychopharmacol J Eur Coll Neuropsychopharmacol. 2006;16(4):281-7.

34. Bares M, Novak T, Kopecek M, Stopkova P, Kozeny J, Hoschl C. The early improvement of depressive symptoms as a potential predictor of response to antidepressants in depressive patients who failed to respond to previous antidepressant treatments. Analysis of naturalistic data. Eur Psychiatry J Assoc Eur Psychiatr. 2012;27(7):522-7.

35. Henkel V, Seemuller F, Obermeier M, Adli M, Bauer M, Mundt $\mathrm{C}$, et al. Does early improvement triggered by antidepressants predict response/remission? Analysis of data from a naturalistic study on a large sample of inpatients with major depression. J Affect Disord. 2009;115(3):439-49.

36. Papakostas GI, Perlis RH, Scalia MJ, Petersen TJ, Fava M. A meta-analysis of early sustained response rates between antidepressants and placebo for the treatment of major depressive disorder. J Clin Psychopharmacol. 2006;26(1):56-60.

37. Tadic A, Helmreich I, Mergl R, Hautzinger M, Kohnen R, Henkel $\mathrm{V}$, et al. Early improvement is a predictor of treatment outcome in patients with mild major, minor or subsyndromal depression. J Affect Disord. 2010;120(1-3):86-93.

38. Szegedi A, Muller MJ, Anghelescu I, Klawe C, Kohnen R, Benkert O. Early improvement under mirtazapine and paroxetine predicts later stable response and remission with high sensitivity in patients with major depression. J Clin Psychiatry. 2003;64(4):413-20.

39. Nierenberg AA, McLean NE, Alpert JE, Worthington JJ, Rosenbaum JF, Fava M. Early nonresponse to fluoxetine as a predictor of poor 8-week outcome. Am J Psychiatry. 1995;152(10): 1500-3.

40. Croxtall JD, Scott LJ. Olanzapine/fluoxetine: a review of its use in patients with treatment-resistant major depressive disorder. CNS Drugs. 2010;24(3):245-62.

41. Stewart JW. Treating depression with atypical features. J Clin Psychiatry. 2007;68(Suppl. 3):25-9.

42. Liebowitz MR, Quitkin FM, Stewart JW, McGrath PJ, Harrison WM, Markowitz JS, et al. Antidepressant specificity in atypical depression. Arch Gen Psychiatry. 1988;45(2):129-37.

43. Stewart JW, McGrath PJ, Fava M, Wisniewski SR, Zisook S, Cook I, et al. Do atypical features affect outcome in depressed outpatients treated with citalopram? Int J Neuropsychopharmacol. 2009;3:1-16.

44. Fava M, Rush AJ, Alpert JE, Balasubramani GK, Wisniewski SR, Carmin $\mathrm{CN}$, et al. Difference in treatment outcome in outpatients with anxious versus nonanxious depression: a STAR *D report. Am J Psychiatry. 2008;165(3):342-51.

45. Nelson JC, Thase ME, Bellocchio EE, Rollin LM, Eudicone JM, McQuade RD, et al. Efficacy of adjunctive aripiprazole in patients with major depressive disorder who showed minimal response to initial antidepressant therapy. Int Clin Psychopharmacol. 2012;27(3):125-33. 
46. Nelson JC, Mankoski R, Baker RA, Carlson BX, Eudicone JM, Pikalov A, et al. Effects of aripiprazole adjunctive to standard antidepressant treatment on the core symptoms of depression: a post-hoc, pooled analysis of two large, placebo-controlled studies. J Affect Disord. 2010;120(1-3):133-40.

47. Trivedi MH, Thase ME, Fava M, Nelson CJ, Yang H, Qi Y, et al. Adjunctive aripiprazole in major depressive disorder: analysis of efficacy and safety in patients with anxious and atypical features. J Clin Psychiatry. 2008;69(12):1928-36.

48. Thase ME, Demyttenaere K, Earley WR, Gustafsson U, Udd M, Eriksson H. Extended release quetiapine fumarate in major depressive disorder: analysis in patients with anxious depression. Depress Anxiety. 2012;29(7):574-86.

49. Bauer M, El-Khalili N, Datto C, Szamosi J, Eriksson H. A pooled analysis of two randomised, placebo-controlled studies of extended release quetiapine fumarate adjunctive to antidepressant therapy in patients with major depressive disorder. J Affect Disord. 2010;127(1-3):19-30.

50. Berman RM, Thase ME, Trivedi MH, Hazel JA, Marler SV, McQuade RD, et al. Long-term safety and tolerability of openlabel aripiprazole augmentation of antidepressant therapy in major depressive disorder. Neuropsychiatr Dis Treat. 2011;7: 303-12.

51. Liebowitz M, Lam RW, Lepola U, Datto C, Sweitzer D, Eriksson $\mathrm{H}$. Efficacy and tolerability of extended release quetiapine fumarate monotherapy as maintenance treatment of major depressive disorder: a randomized, placebo-controlled trial. Depress Anxiety. 2010;27(10):964-76.

52. Corya SA, Perlis RH, Keck PE Jr, Lin DY, Case MG, Williamson DJ, et al. A 24-week open-label extension study of olanzapinefluoxetine combination and olanzapine monotherapy in the treatment of bipolar depression. J Clin Psychiatry. 2006;67(5): 798-806.
53. Jing Y, Kalsekar I, Curkendall SM, Carls GS, Bagalman E, Forbes RA, et al. Intent-to-treat analysis of health care expenditures of patients treated with atypical antipsychotics as adjunctive therapy in depression. Clin Ther. 2011;33(9):1246-57.

54. Shen H, He MM, Liu H, Wrighton SA, Wang L, Guo B, et al. Comparative metabolic capabilities and inhibitory profiles of CYP2D6.1, CYP2D6.10, and CYP2D6.17. Drug Metab Dispos Biol Fate Chem. 2007;35(8):1292-300.

55. Chong SA, Tan CH, Khoo YM, Lee HS, Wong KE, Ngui F, et al. Clinical evaluation and plasma clozapine concentrations in Chinese patients with schizophrenia. Ther Drug Monit. 1997;19(2): 219-23.

56. Chen SJ, Hsiao YL, Shen TW, Chen ST. The effectiveness and safety of adjunctive aripiprazole in Taiwanese patients with antidepressant-refractory major depressive disorder: a prospective, open-label trial. J Clin Psychopharmacol. 2012;32(1):56-60.

57. Pae CU, Patkar AA, Jun TY, Lee C, Masand PS, Paik IH. Aripiprazole augmentation for treatment of patients with inadequate antidepressants response. Depress Anxiety. 2007;24(7):522-6.

58. Yoshimura RKT, Hori H, Ikenouchi-Sugita A, Katsuki A, Umene-Nakano W, Iwata N, Nakamura J. Comparison of the efficacy between paroxetine and sertraline augmented with aripiprazole in patients with refractory major depressive disorder. Prog Neuropsychopharmacol Biol Psychiatry. In Press.

59. Fredman SJ, Fava M, Kienke AS, White CN, Nierenberg AA, Rosenbaum JF. Partial response, nonresponse, and relapse with selective serotonin reuptake inhibitors in major depression: a survey of current "next-step" practices. J Clin Psychiatry. 2000; 61(6):403-8.

60. Kemp DE, Calabrese JR, Eudicone JM, Ganocy S, Tran QV, McQuade RD, et al. Predictive value of early improvement in bipolar depression trials: a post-hoc pooled analysis of two 8-week aripiprazole studies. Psychopharmacol Bull. 2010;43(2):5-27. 